\title{
Potential of a Hydrometallurgical Recycling Process for Catalysts to Cover the Demand for Critical Metals, Like PGMs and Cerium
}

\author{
STEFAN STEINLECHNER ${ }^{1,2}$ and JÜRGEN ANTREKOWITSCH ${ }^{1}$ \\ 1.-Chair of Nonferrous Metallurgy, University of Leoben, Franz-Josef-Str. 18, 8700 Leoben, \\ Austria. 2.—e-mail: stefan.steinlechner@unileoben.ac.at
}

The metals from the platinum group are used in many different industries, for example dental, jewelry, and chemicals. Nevertheless, the most important use is based on their catalytic properties. Approximately 50\% of platinum and palladium are used as automotive and industrial catalysts. In case of rhodium, an even higher percentage (around $80-90 \%$ ) is used as an alloying element in the active layer of different catalysts. The high required amount of $300-900 \mathrm{~kg}$ of treated ore to obtain approximately $1 \mathrm{~g}$ of PGM is responsible for the high prices. On average, the contents in the ore of $\mathrm{Pt}$ and $\mathrm{Pd}$ are 5-10 times higher than $\mathrm{Rh}$ and $\mathrm{Ru}$ and around 50 times higher than Ir and Os. Additionally, the regional limitation of ore bodies leads to a strong dependence on mainly South Africa and Russia as PGM suppliers. Based on the strong discrepancy in supply and demand of PGM's around the world, recycling of catalysts is mandatory and meaningful from the ecological and economical point of view. Based on the high prices of PGM, the industry is forced to improve the efficiency of catalysts, which is done by improving the wash coat technology. By using rare-earth elements, like cerium oxide, the surface can be increased and the ability to supply oxygen is secured. As a side effect, cerium as an additional critical element is introduced into the recycling circuit of catalytic converters, forming a further valuable component and forming a major challenge for common pyrometallurgical converter recycling. Therefore, this article introduces a hydrometallurgical process, developed together with Railly\&Hill Inc., for PGM as well as cerium recovery from catalytic converters.

\section{INTRODUCTION}

It is mandatory and meaningful to carry out a recycling of PGM containing material around the world. Although primary PGM reserves are high enough to last for several decades, temporary shortages as well as price peaks are possible due to several reasons. ${ }^{1}$

First of all, like shown in Fig. 1, a strong discrepancy of suppliers (mainly Africa and Russia) and consumers (Europe, China, Japan, and North America) exists. Worldwide reserves of PGM are estimated by the U.S. Geological Survey (USGS) in 2013 to be present to $95 \%$ in South Africa, $1.6 \%$ in Russia, and the remaining $2.8 \%$ in the rest of the world ${ }^{2}$ underlining the strong dependence on Africa's supply. Due to the presence of permafrost soil in Russia and deep mines in Africa, the processing of the ore is cost intensive. A peak in demand cannot easily be compensated, for instance in the case of Russia, because their PGMs are produced as a byproduct of nickel. Russia would have to increase their production of nickel, leading to a higher supply, and thus to a lower price for their main product (nickel), to increase the PGM production (see Fig. 1). ${ }^{3}$

A somewhat similar case, even more drastic, can be found in the area of rare-earth elements. The element cerium is of interest in this context due to its utilization in the wash coats of catalysts. By 2005, China accounted for $96 \%$ of global rare earth production, including more than $99 \%$ of heavy rare 
(a) Pd supply by region

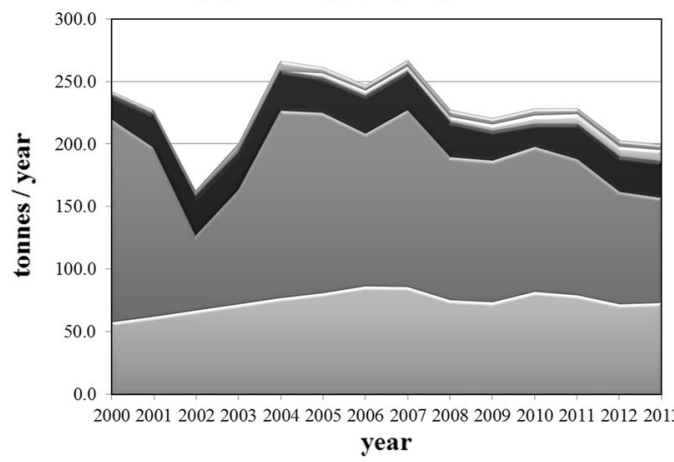

Rh supply by region

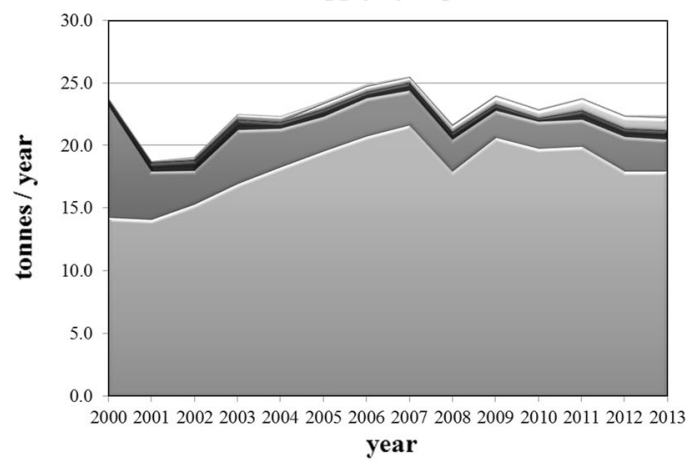

Pt supply by region

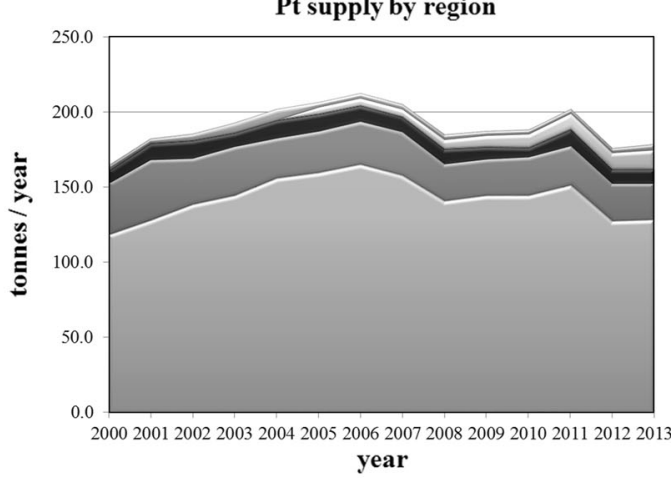

(b) Pd demand by region

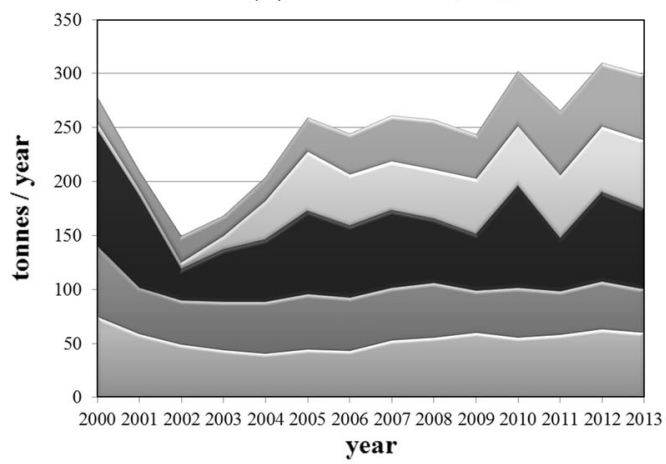

$\varpi$ Rest of the World

$\backsim$ China

- North America

Japan

$\square$ Europe
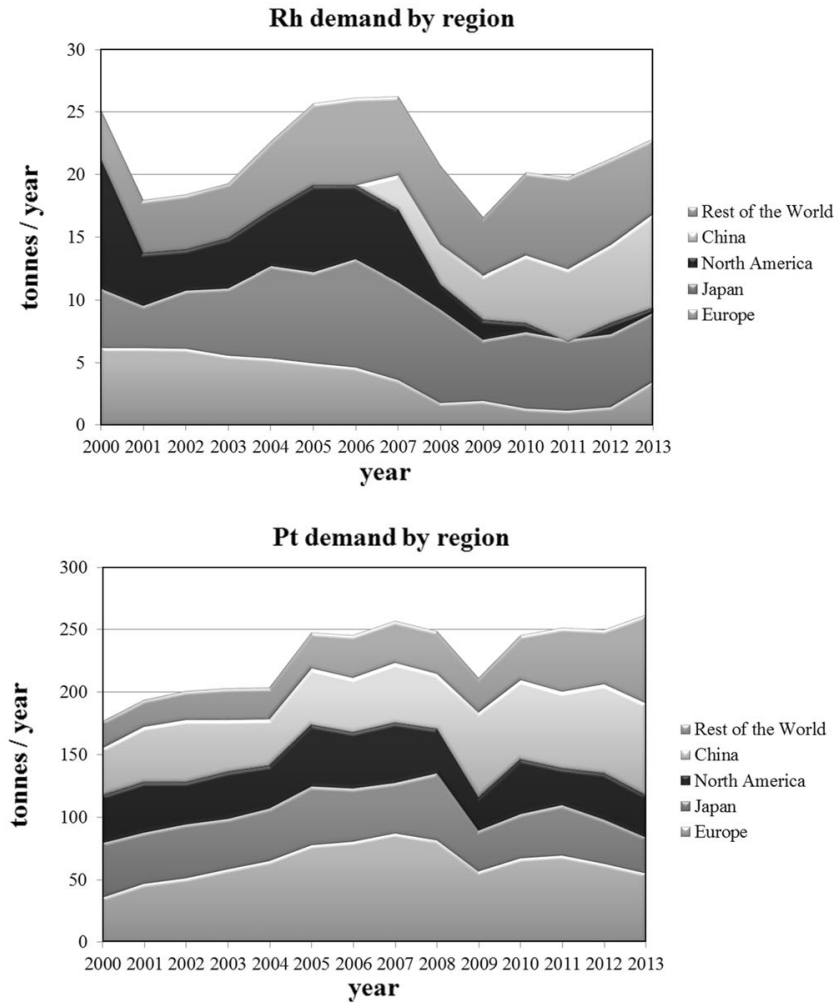

Fig. 1. Platinum, palladium, and rhodium supply (a) and demand (b) by region and their development since 2000 (data based on Ref. 3).

earth oxides. In 2008, the production of rare-earth elements peaked, accounting for $97 \%$ of global production. Slowly, the rest of the world is trying to open new resources to become more independent, but the chemistry is complex and the rest of the world will have its main impact on light rare earths, like cerium, and not on the heavy ones, where a strong dependence will remain.

A second reason for price peaks is the fact that, as shown in Fig. 2, the main utilization area of platinum and palladium as well as cerium and rhodium is the automotive industry in form of catalytic converters. Statistical data show that around 55\% of palladium and platinum are used in automotive catalysts ( $40 \%$ of $\mathrm{Pt}$ and $67 \%$ of $\mathrm{Pd}),{ }^{3}$ which makes it clear why the supply is strongly dependent on the automotive market.

\section{POTENTIAL OF CATALYSTS AND THEIR PGM CONTENT DEVELOPMENT}

Based on the main usage of PGMs and cerium in catalysts, Table I shows, based on the pollutant category (EURO I-IV), engine displacement, and car type (diesel or gasoline also known as the Otto engine), the increasing potential for recycling and the potential for recovering critical elements from spent converters, securing the supply for those elements.

Although the technology for catalysts production has improved, the PGM load still increases over the years. The reason for this is the steadily increasing comfort of modern cars. Because of the increase of electronics and safety equipment, the weight of an average car has increased over the years, leading to 

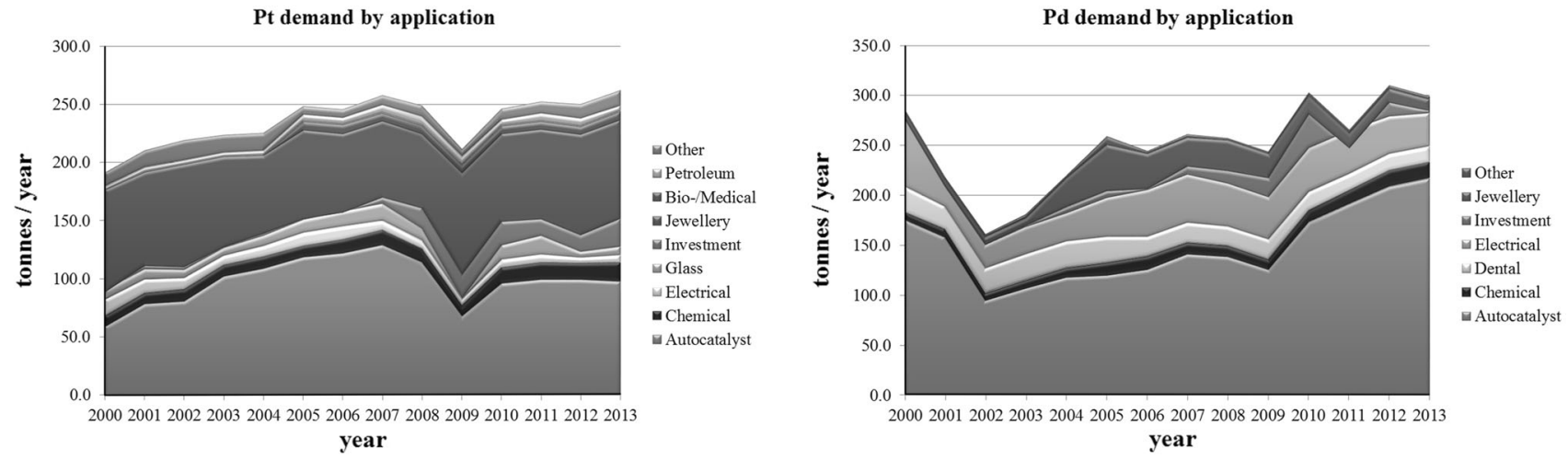

Fig. 2. Platinum and palladium demand by application area (data based on Ref. 3).

Table I. PGM content of spent automotive car catalysts at the end of their life cycle ${ }^{5,6}$

\begin{tabular}{|c|c|c|c|c|c|c|c|}
\hline \multirow[b]{3}{*}{$\begin{array}{l}\text { Pollutant } \\
\text { category }\end{array}$} & \multirow[b]{3}{*}{$\begin{array}{l}\text { Displacement of } \\
\text { engine (L) }\end{array}$} & \multicolumn{4}{|c|}{ Otto vehicle } & \multicolumn{2}{|c|}{ Diesel vehicle } \\
\hline & & \multicolumn{4}{|c|}{ PGM, g/car } & \multirow[b]{2}{*}{$\begin{array}{l}\text { Displacement } \\
\text { of engine (L) } \\
\end{array}$} & \multirow[b]{2}{*}{$\begin{array}{l}\text { PGM, } \\
\text { g/car } \\
\end{array}$} \\
\hline & & $\mathbf{P t}$ & Pd & $\mathbf{R h}$ & Total & & \\
\hline \multirow[t]{3}{*}{ G-Kat 87-90 } & $<1.4$ & 0.95 & 0.00 & 0.19 & 1.14 & & \\
\hline & $1.4-2$ & 1.43 & 0.00 & 0.29 & 1.71 & $<2$ & \\
\hline & $>2$ & 2.09 & 0.00 & 0.43 & 2.52 & $>2$ & \\
\hline \multirow[t]{3}{*}{ Euro I } & $<1.4$ & 0.95 & 0.00 & 0.19 & 1.14 & & \\
\hline & $1.4-2$ & 1.71 & 0.00 & 0.33 & 2.04 & $<2$ & \\
\hline & $>2$ & 2.76 & 0.00 & 0.57 & 3.33 & $>2$ & \\
\hline \multirow[t]{3}{*}{ Euro II } & $<1.4$ & 0.29 & 1.14 & 0.19 & 1.62 & & \\
\hline & $1.4-2$ & 0.38 & 2.00 & 0.29 & 2.66 & $<2$ & 1.43 \\
\hline & $>2$ & 2.09 & 3.04 & 0.67 & 5.80 & $>2$ & 4.28 \\
\hline \multirow[t]{3}{*}{ Euro III } & $<1.4$ & 0.10 & 2.47 & 0.29 & 2.85 & & \\
\hline & $1.4-2$ & 0.48 & 2.76 & 0.29 & 3.52 & $<2$ & 4.09 \\
\hline & $>2$ & 0.57 & 3.71 & 0.67 & 4.94 & $>2$ & 8.55 \\
\hline \multirow[t]{3}{*}{ Euro IV } & $<1.4$ & 0.57 & 0.95 & 0.29 & 1.81 & & \\
\hline & $1.4-2$ & 0.67 & 2.85 & 0.48 & 3.99 & $<2$ & 4.75 \\
\hline & $>2$ & 0.48 & 4.75 & 0.67 & 5.89 & $>2$ & 8.55 \\
\hline
\end{tabular}

the necessity of stronger engines and bigger or better catalysts, which goes with a higher consumption of PGMs per car. The introduction of Euro II also dictated the use of catalysts in diesel engines. With the introduction of Euro IV, most of them got additional particle filters, also partly coated with platinum. Therefore, the PGM load per car includes also the PGM load of the particle filters in the case of Euro IV.

Based on the upcoming additional production of vehicles in China and India, in future the backflow of spent automotive catalysts will increase steadily. The already huge potential of catalyst recycling (more than 50\% of PGM and around 50\% of cerium are used in this area) for covering the supply gap of critical elements in Europe, America, and so on, increases steadily. At the moment, two trends are competing with each other in catalytic converter production. On the one hand, the PGM load is increased because of stricter emission limits, whereas on the other hand, better motor management, fuel quality, exhaust gas design, and production technology (such as wash coats) decrease the required amount. But, especially with the last mentioned point, elements such as cerium are more and more introduced by the wash coat into the recycling route of catalysts.

\section{TYPICAL RECYCLING OF SPENT CATALYSTS}

Based on the applied technology for recycling of PGM containing catalytic converters, different advantages and disadvantages are present. Figure 3 shows a rough overview of possible technologies, which can be applied to recycle automotive and industrial catalysts.

Within the pyrometallurgical route, the common method for PGM recovery is to melt down the complete monolith, recovering the precious metals in a collector metal bath. Because of the material used for the honeycomb structure, temperatures of $1500^{\circ} \mathrm{C}$ up to $1900^{\circ} \mathrm{C}$, in case of applied plasma technology, are required to be able to melt the 


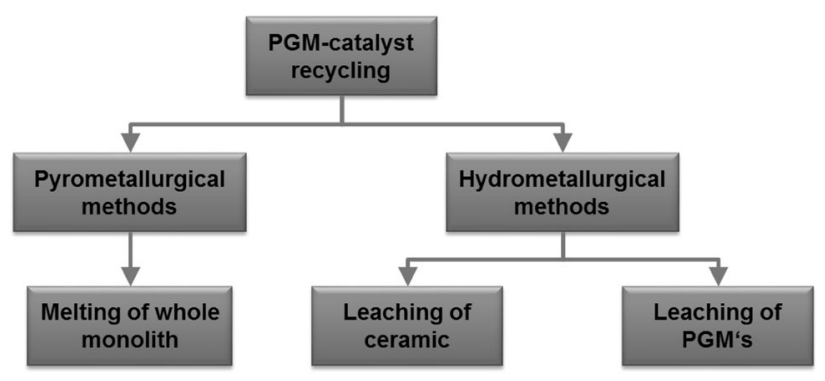

Fig. 3. Catalytic converter recycling technology overview.

complete monolith after flux addition. Because of these high temperatures, metals like rhodium, with a melting point of $1966^{\circ} \mathrm{C}$, are not always liquid in this process and therefore need to be dissolved in the collector metal. As a result of the fine distribution of metal particles in the slag, a high turbulence is required to contact the collector metal droplets with the valuable metal particles before they separate from the slag based on their density. For achieving such high temperatures, plasma, slag resistance, or electric arc furnace are used. Catalyst recycling is commonly carried out parallel to a nickel, cobalt, and copper production, which is the reason why they are charged together with such ores. However, even in case of the pyrometallurgical route, a hydrometallurgical enrichment step as well as a separation step for the PGMs has to be carried out after the melting. Rare-earth elements, present in the wash coat of the catalytic converters, are typically diluted by the molten material and as a consequence are dumped with the remaining slag of the pyrometallurgical process.

The hydrometallurgical processing possibilities are split into leaching of the ceramic material, leaving the PGM behind as solids or dissolution of the precious metals selectively from the monolith material. A wide variety of leaching agents can be used to dissolve the material. The PGMs are relatively resistant to acid dissolution; nevertheless, the most common method is to leach with strong acids under the addition of different possible oxidation agents. The most common leaching agent to form soluble chloro-complexes is HCl. The PGM-loaded solution is treated then further to access the PGM by cementation, solvent extraction, or the adsorption on ion exchange compounds.

The second possible processing route is to dissolve the monolith, leaving the precious metals in the solid residue. The main disadvantage is the high amount of process solution and consequently high amounts of wastewater.

In most of the routes, which are mainly pyrometallurgical, these mentioned rare earths like cerium are not recovered but are dumped with the process slag. Therefore, this article introduces a hydrometallurgical process, running in a closed loop, with the advantage of an additional cerium recovery next to the advantage of no or very low amounts of waste streams.

\section{POTENTIAL OF HYDROMETALLURGICAL PROCESS TO COVER SUPPLY OF CRITICAL ELEMENTS}

Because an article describing the process in detail was published, ${ }^{7,8}$ this article will only give a short summary of the key steps. It is based on a common leaching in chloride media, enabling also the dissolution and recovery of cerium from the wash coat, representing an interesting opportunity to recover also the rare-earth element cerium. The huge potential of minimizing the supply risk by recovery of cerium also from recycled catalysts instead of importing from China was also described by USGS. ${ }^{9}$ An economic advantage compared with other hydrometallurgical processes as well as the very common pyrometallurgical recycling of catalysts is present. Figure 4 shows the block diagram of the general process.

The important process steps of the main solution loop (see Fig. 4) are described in the following. The milled monolith material is leached by hydrochloric acid and the addition of $\mathrm{H}_{2} \mathrm{O}_{2}$ as oxidant. To obtain optimum efficiency rates, special conditions, like specific redox potential, low $\mathrm{pH}$, specified solid to liquid ratio, stirring rate, and temperature have to be chosen. Many authors, such as Harjanto et al., ${ }^{10}$ investigated the best leaching conditions in different media. During this step, soluble chlorocomplexes are formed, as this is shown in Eq. 1 through 4.

$$
\mathrm{Pt}_{(\mathrm{s})}+6 \mathrm{H}^{+}+2 \mathrm{HO}_{2}^{-}+6 \mathrm{Cl}^{-} \rightarrow\left[\mathrm{PtCl}_{6}\right]^{2-}+4 \mathrm{H}_{2} \mathrm{O}
$$

$$
\begin{gathered}
\mathrm{Pd}_{(\mathrm{s})}+3 \mathrm{H}^{+}+\mathrm{HO}_{2}^{-}+4 \mathrm{Cl}^{-} \rightarrow\left[\mathrm{PdCl}_{4}\right]^{2-}+2 \mathrm{H}_{2} \mathrm{O}(2) \\
\mathrm{Rh}_{(\mathrm{s})}+4.5 \mathrm{H}^{+}+1.5 \mathrm{HO}_{2}^{-}+6 \mathrm{Cl}^{-} \rightarrow\left[\mathrm{RhCl}_{6}\right]^{3-}+3 \mathrm{H}_{2} \mathrm{O}
\end{gathered}
$$

$$
\mathrm{Ce}_{(\mathrm{s})}+4.5 \mathrm{H}^{+}+1.5 \mathrm{HO}_{2}^{-}+4 \mathrm{Cl}^{-} \rightarrow\left[\mathrm{CeCl}_{4}\right]^{-}+3 \mathrm{H}_{2} \mathrm{O}
$$

A positive aspect is the formation of $\mathrm{H}_{2} \mathrm{O}$, which is balancing a part of the loss of the obtained filter cakes. Next to the present precious metals, the cerium forms a soluble chloro-complex (see Eq. 4) and therefore can be found in the pregnant solution after the filtration step. Described by Cotton, ${ }^{11}$ the obtained liquor can be red to brown, green, or yellow depending on the oxidation stage and the amount of dissolved PGMs and cerium, as well as the possible 


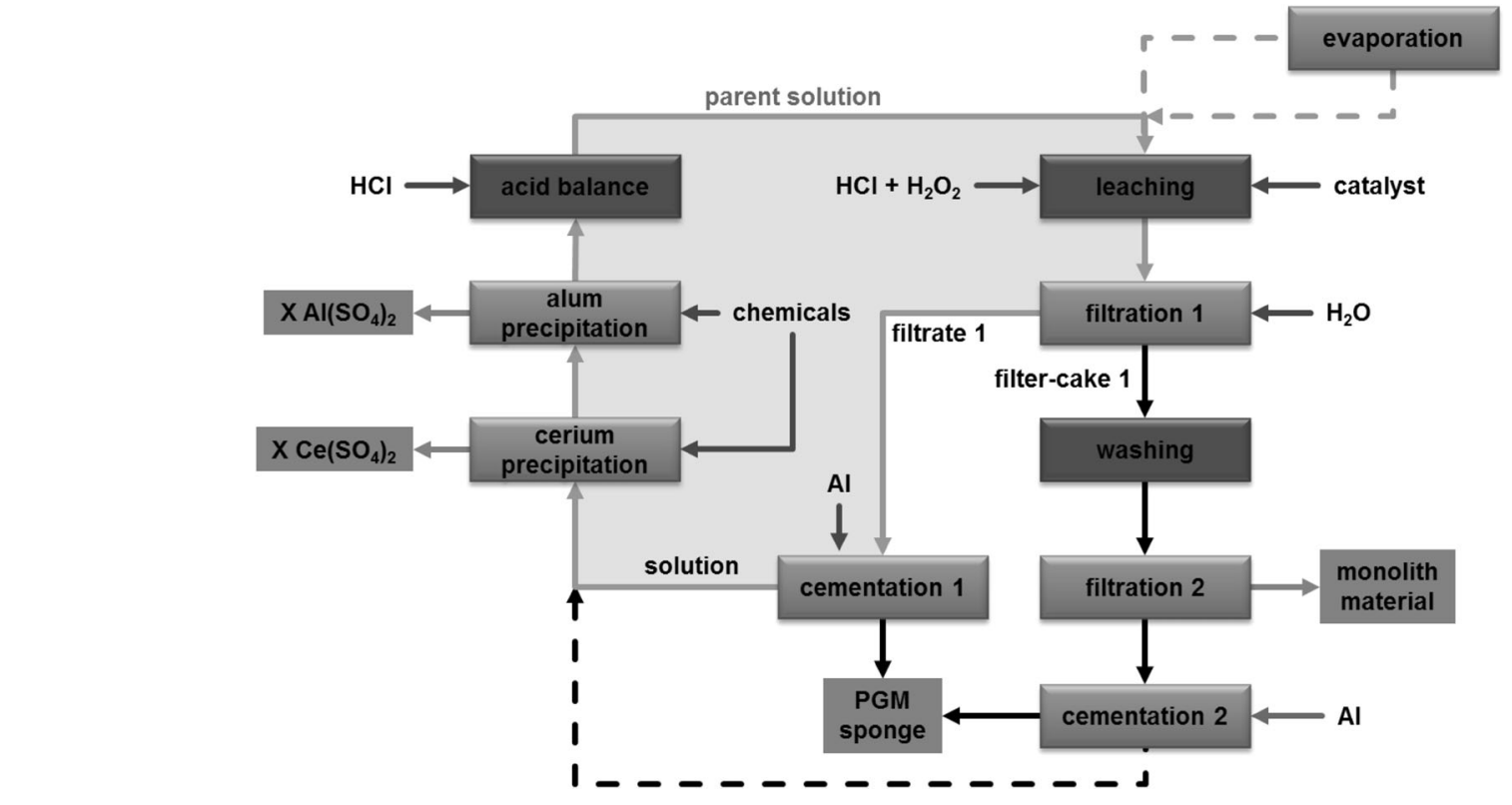

Fig. 4. Block diagram of catalyst treatment process. ${ }^{7,8}$

impurities present. Shown in Eq. 5 is an occurring side reaction, the dissolution of $\mathrm{Al}_{2} \mathrm{O}_{3}$, which is leached first from the monolith material (typically cordierite).

$$
\mathrm{Al}_{2} \mathrm{O}_{3(\mathrm{~s})}+6 \mathrm{H}^{+} \rightarrow 2 \mathrm{Al}^{3+}+3 \mathrm{H}_{2} \mathrm{O}
$$

This is no problem from the point of dissolved aluminum because during the cementation step, aluminum is used to cement the PGMs from the pregnant solution and must be removed during the solution cleaning. Equations 6 through 8 show the cementation reactions, wherein hydrogen is formed next to the metallic PGM sponge.

$2 \mathrm{Al}_{(\mathrm{s})}+2 \mathrm{H}^{+}+\left[\mathrm{PtCl}_{6}\right]^{2-} \rightarrow \mathrm{Pt}_{(\mathrm{s})}+2 \mathrm{Al}^{3+}+6 \mathrm{Cl}^{-}+\mathrm{H}_{2(\mathrm{~g})}$

$$
4 \mathrm{Al}_{(\mathrm{s})}+6 \mathrm{H}^{+}+3\left[\mathrm{PdCl}_{4}\right]^{2-} \rightarrow 3 \mathrm{Pd}_{(\mathrm{s})}+4 \mathrm{Al}^{3+}+12 \mathrm{Cl}^{-}+3 \mathrm{H}_{2(\mathrm{~g})}
$$

$$
2 \mathrm{Al}_{(\mathrm{s})}+3 \mathrm{H}^{+}+\left[\mathrm{RhCl}_{6}\right]^{3-} \rightarrow \mathrm{Rh}_{(\mathrm{s})}+2 \mathrm{Al}^{3+}+6 \mathrm{Cl}^{-}+1.5 \mathrm{H}_{2(\mathrm{~g})}
$$

Because a part of the monolith is dissolved and the solution already carries aluminum, it is meaningful to use metallic aluminum for the cementation reaction because no new impurity is introduced into the system.

The dissolution reactions and the cementation step are the reasons why an acid-balancing step is required because of the occurring reaction to hydrogen.

Both elements removed within the solutioncleaning step form a usable product and add value to the process. Equations 9 and 10 show the chemical reactions to remove aluminum as alum and cerium as a double sulfate from the solution.

$$
\begin{gathered}
{\left[\mathrm{CeCl}_{4}\right]^{-}+1.5 \mathrm{H}_{2} \mathrm{SO}_{4}+0.5 \mathrm{Na}_{2} \mathrm{SO}_{4}} \\
\rightarrow \mathrm{NaCe}\left(\mathrm{SO}_{4}\right)_{2}+4 \mathrm{Cl}^{-}+3 \mathrm{H}^{+}
\end{gathered}
$$

$$
\mathrm{Al}^{3+}+2 \mathrm{H}_{2} \mathrm{SO}_{4}+\mathrm{KCl} \rightarrow \mathrm{KAl}\left(\mathrm{SO}_{4}\right)_{2}+\mathrm{Cl}^{-}+4 \mathrm{H}^{+}
$$

Equations 9 and 10 both lower the $\mathrm{pH}$ by producing hydrogen ion in solution, contrary to the consumption shown in Eqs. 6 through 8, which consume and partly balance each other. The last step is to add acid or water to adjust the $\mathrm{pH}$ of the solution.

\section{POSSIBLE UTILIZATION OF BY-PRODUCTS OF THE HYDROMETALLURGICAL TREATMENT}

The aim of the described process is to form products instead of residues. In case of the introduced process, no waste streams are formed; instead, there are four marketable products. The main product is the cemented PGM sponge, which can be sold easily to refineries or can be processed by a common hydrometallurgical method to separate PGM salts or metals. Second, the remaining grinded monolith from the leaching step can be used in refractory 
production based on its main compounds $\mathrm{SiO}_{2}$, $\mathrm{Al}_{2} \mathrm{O}_{3}$, and $\mathrm{MgO}$. The alum has three main properties that influence its utilization. It can act as bleaching agent; the sulfate ions are antibacterial and it inhibits microbes. Therefore, typical uses of this product are in cosmetics (deodorant, etc.), the paper industry, and medical applications. The cerium double sulfate can be sold as is or converted to an oxide by a temperature treatment, evaporating $\mathrm{SO}_{2}$, or an alkaline digestion.

\section{SUMMARY AND CONCLUSION}

The continuously ongoing optimization of technology for emission control of cars and trucks, forced by stricter environmental legislations, leads to more and more complex compositions of catalytic converters. An apparently example is the utilization of cerium in the wash coats to influence the properties positively and minimize the required precious metals content.

Today, the typical way of recycling is the processing of spent catalysts in a pyrometallurgical route. On the one hand, this is a very flexible process concerning present impurities. On the other hand, it consumes a lot of energy, which is not necessary in case of hydrometallurgical concepts. Within the introduced hydrometallurgical process it further is possible to recover also critical elements, like the mentioned rare-earth element cerium, beside the precious metals, forming a valuable byproduct. Typical recovery rates for platinum and palladium, representing more than $9 / 10$ of the overall PGM content in the grinded catalysts mixture (input material), are above 97\%. Rhodium, which is representing less than $1 / 10$ of the PGM content of the input material, can be recovered up to 93\%, depending strongly on the chosen leaching conditions. The cerium recovery is strongly dependent on the morphology of the monolith. Furthermore, it is possible to use also the leached monolith, which represents $99 \%$ of the input material, and therefore, the hydrometallurgical process has no solid waste/residue compared with the pyrometallurgical route, where the whole monolith has to be melted down (consuming a lot of energy) and ends up in the process slag, which is dumped. Besides this, a faster metal access of PGMs can be realized due to the direct cementation of an enriched PGM product (sponge), which has to be mentioned as additional advantage. Another important point is the possibility to operate in small-scale facilities. This offers the chance to enlarge the process chain of spent catalytic dealers, in regions where newly generated residues or effluents would cause problems. By this, long transportation distances of raw material, which in the case pyrometallurgy is the only acceptable way due to the high value of the material, is avoided, contributing again to the environment.

\section{REFERENCES}

1. Swiss Academy of Engineering Sciences, Seltene Metalle-Rohstoffe fur Zukunftstechnologien [Rare Metals-Raw Materials for Future Technologies] (Zurich, Switzerland: Swiss Academy of Engineering Sciences, 2010), www.satw. $\mathrm{ch} /$ publikationen/schriften/SelteneMetalle.pdf.

2. U.S. Geological Surveys, Mineral Commodity Summaries 2013 (Reston, VA: U.S. Geological Surveys, 2013), www.mi nerals.usgs.gov/minerals/pubs/mcs/2013/mcs2013.pdf.

3. J. Matthey, Market Data Tables (Hertfordshire, U.K.: Johnson Matthey Precious Metals Management), www.pla tinum.matthey.com/publications/market-data-tables.

4. D. Merriman, Royal Society of Chemistry Environmental Chemistry Group 2013-A Review of the Global Supply of Rare Earths (London, U.K.: Roskill Consulting Group Ltd., 2013), www.rsc.org/images/David-Merriman_tcm18-230229. pdf.

5. C. Hagelüken, Paper presented at 3rd European Workshop on Spent Catalysts, (Berlin, Germany, 8-9 February 2006).

6. C. Hagelüken, M. Buchert, and H. Stahl, Stoffströme der Platingruppenmetalle [Material Flows of the Platinum Group Metals] (Clausthal-Zellerfeld, Germany: GDMB Medienverlag, 2005).

7. S. Steinlechner and J. Antrekowitsch, REWAS 2013 Enabling Materials Resource Sustainability, ed. A. Kfithyld, C.E.M. Meskers, R.E. Kirchain, G.K. Krumdick, B. Mishra, M.A. Reuter, C. Wang, M.E. Schlesinger, G. Gaustad, D. Lados, and J.S. Spangenberger (New York: Wiley, 2013), pp. 361-369.

8. S. Steinlechner, Hydrometallurgy 2014, Vol. II (Montreal, QC: MetSOC of the CIM, 2014), pp. 489-498.

9. D.I. Bliewas, Potential for Recovery of Cerium Contained in Automotive Catalytic Converters (Reston, VA: U.S. Geological Survey, 2013).

10. S. Harjanto, Y. Cao, A. Shibayama, I. Naitoh, T. Nanami, K. Kasahara, Y. Okumura, K. Liu, and T. Fujita, Mater. Trans. 47, 129-135 (2006).

11. S.A. Cotton, Chemistry of Precious Metals (New York: Blackie Academic \& Professional, 1997). 